\title{
Abstracts
}

\section{Faculty of Accident and Emergency Medicine annual scientific meeting, November 2001 (Prize and oral abstracts)}

\section{SSL Prize session}

\section{COST-EFFECTIVENESS OF MANAGEMENT STRATEGIES FOR PATIENTS WITH ACUTE, UNDIFFERENTIATED CHEST PAIN}

S. Goodacre, N. Calvert. Medical Care Research Unit, School of Health and Related Research, Regent Court, 30 Regent Street, Sheffield S1 4DA.

Background: Patients presenting to hospital with acute chest pain, undiagnosed by electrocardiograph and clinical assessment, have a low, but important, risk of significant myocardial ischaemia. Strategies for detecting ischaemia in this situation have received little formal evaluation and vary from low cost, poor effectiveness (discharging all home) to high cost, high effectiveness (admission and intensive investigation). This study aimed to compare the relative cost-effectiveness of potential diagnostic strategies.

Methods: Decision analysis modelling was used to determine the incremental cost per life saved for each of five strategies, compared to the next most effective alternative, or a baseline strategy of discharging all patients home without further testing

Results: The incremental cost per life saved increased with the complexity of each diagnostic strategy, relative to the next most effective. Cardiac enzyme testing alone cost $£ 92,352$ per life saved compared to discharge without testing. Adding 2-6 hours of observation and repeat enzyme testing cost an extra £99,277 per life saved. Adding exercise testing to this strategy cost $£ 163,755$ per life saved. A strategy of overnight admission, enzyme and exercise testing was markedly more expensive with a marginal cost of $£ 707,066$ per life saved, while a strategy consisting of overnight admission without exercise testing was subject to extended dominance. Sensitivity analysis revealed that the results were sensitive to variation in the cost providing each strategy.

Conclusion: Strategies consisting of 2-6 hours observation and repeat enzyme testing, either with or without exercise testing, incur similar costs per life saved to presently funded interventions for coronary heart disease, while strategies requiring hospital admission may be considered to be prohibitively poor value for money. Empirical validation of the true costs and effects of these strategies is essential prior to widespread implementation.

RANDOMISED, CONTROLLED STUDY OF NON-INVASIVE VENTILATION IN THE TREATMENT OF A\&E PATIENTS WITH ACUTE, CARDIOGENIC PULMONARY OEDEMA (POSITIVE PRESSURE IN PULMONARY OEDEMA (3PO) STUDY)

S. D. Crane, A. J. Gray, M. W. Elliott, K. Richards, P. Gilligan. Accident and Emergency Department, St James's University Hospital, Beckett Street, Leeds, West Yorkshire LS9 TTF.

Aim: To evaluate the use of two types of non-invasive ventilation in the treatment of patients attending Accident and Emergency with acute, cardiogenic pulmonary oedema (LVF).

Study design and patients: A pragmatic, randomised trial of CPAP versus Bilevel versus standard face mask oxygen in patients presenting with acute, cardiogenic pulmonary oedema. We included patients with clinical acute LVF with a respiratory rate above 23 breaths per minute (bpm), arterial blood $\mathrm{pH}<7.35$ and in whom a chest x-ray confirmed pulmonary oedema.

Interventions: All patients received oxygen, frusemide, nitrates and/or opiates. The CPAP group received continuous airways pressure via face mask at $10 \mathrm{cmH}_{2} \mathrm{O}$; the Bilevel group received 15 $\mathrm{cmH}_{2} \mathrm{O}$ inspiratory pressure and $5 \mathrm{cmH}_{2} \mathrm{O}$ expiratory pressure. The control group received oxygen via a non-rebreathing face mask.

Main outcome measure: This was treatment success within two hours of study entry; i.e. reversal of acidosis ( $\mathrm{pH}>7.35$ ) with a respiratory rate of less than $22 \mathrm{bpm}$ and oxygen saturation of $90 \%$ or above.

Results: The table describes physiological changes observed in the three groups over the study period.

\begin{tabular}{|c|c|c|c|c|c|c|}
\hline \multirow[b]{2}{*}{$\begin{array}{l}\text { Parameter } \\
\text { Mean (SD) }\end{array}$} & \multicolumn{2}{|c|}{$\begin{array}{l}\text { Face Mask } \\
(\mathrm{n}=20)\end{array}$} & \multicolumn{2}{|l|}{$\begin{array}{l}\text { CPAP } \\
(n=19)\end{array}$} & \multicolumn{2}{|l|}{$\begin{array}{l}\text { BiLevel } \\
(n=16)\end{array}$} \\
\hline & $\begin{array}{l}0 \\
\text { mins }\end{array}$ & $\begin{array}{l}120 \\
\text { mins }\end{array}$ & $\begin{array}{l}0 \\
\text { mins }\end{array}$ & $\begin{array}{l}120 \\
\text { mins }\end{array}$ & $\begin{array}{l}0 \\
\text { mins }\end{array}$ & $\begin{array}{l}120 \\
\text { mins }\end{array}$ \\
\hline $\begin{array}{l}\text { Resp Rate } \\
\text { (breaths / min) }\end{array}$ & $30(6)$ & $24(7)$ & 27 (8) & $20(6)$ & $30(6)$ & $20(6)$ \\
\hline Blood Ph & $\begin{array}{l}7.20 \\
(0.08)\end{array}$ & $\begin{array}{l}7.35 \\
(0.04)\end{array}$ & $\begin{array}{l}7.17 \\
(0.11)\end{array}$ & $\begin{array}{l}7.33 \\
(0.077)\end{array}$ & $\begin{array}{l}7.22 \\
(0.07)\end{array}$ & $\begin{array}{l}7.35 \\
(0.07)\end{array}$ \\
\hline $\begin{array}{l}\mathrm{O}_{2} \text { Saturation } \\
(\%)\end{array}$ & $\begin{array}{l}91.3 \\
(8.2)\end{array}$ & $\begin{array}{l}96.1 \\
(3.3)\end{array}$ & $\begin{array}{l}89.6 \\
(10.6)\end{array}$ & $\begin{array}{l}93.7 \\
(6.1)\end{array}$ & $\begin{array}{l}89.1 \\
(12.2)\end{array}$ & $\begin{array}{l}95.2 \\
(4.8)\end{array}$ \\
\hline
\end{tabular}

In the Bilevel group 7 of $16(44 \%)$ reached treatment success at two hours compared to 3 of $20(15 \%)$ in the control group ( $p=0.07$; Fishers Test); in the CPAP group this figure was 7 of $19(37 \%)(p=0.16)$. These improvements were mainly explained by greater reductions in respiratory rate in patients treated with non-invasive ventilation. There were no differences between the groups in terms of intubation rate, myocardial infarction rate, length of hospital stay or survival to discharge.

Conclusions: Non invasive ventilation leads to a more rapid improvement of important physiological variables in the early treatment of LVF within the Accident and Emergency department.

\section{A RANDOMISED TRIAL OF THE SAFETY AND EFFECTIVENESS OF MINOR INJURIES TELEMEDICINE}

J. R. Benger, S. M. Noble, J. M. Kendall, J. Coast. Accident And Emergency Department, Tewkesbury Hospital, Barton Road, Tewkesbury, Gloucestershire GL20 5QN.

Objectives: 1 . To determine the safety of minor injuries telemedicine in comparison to current practice and a gold standard. 2. To assess the clinical effectiveness of minor injuries telemedicine through the medium of a prospective, randomised and blinded clinical trial

Methods: A telemedicine consultation system was installed between a representative peripheral unit and its associated Emergency Department (ED). Recruited patients were separately assessed via the telemedicine link, by an on-site ED specialist and also by a general practitioner (GP) wherever possible, allowing a series of independent treatment plans, blinded to all others, to be drawn up. These were compared with a gold standard established at review to identify potential discrepancies, which were then submitted to an independent expert panel for assessment. Each patient was randomly assigned to follow one of the three treatment plans and reviewed 5-10 days later to assess a range of outcomes related to safety, clinical effectiveness and process of care.

Results: The mean duration of a telemedicine consultation 15.8 min.) was almost twice as long as an onsite ED (3.1 min.) or GP consultation (3.4 min.) ( $p<0.0001$ in both cases). Telemedicine and onsite ED consultations resulted in very similar rates of X-ray (59.2 vs. $60.5 \%$ ), but significantly more patients were given a follow up appointment following telemedicine $(35.8 \%$ vs. $27.5 \%$ : $p<0.0001)$ GPs X-rayed significantly less patients (53.1\%: $p<0.0001$ ), but followed up considerably more than either onsite ED or telemedicine 165.0\%: $p<0.0001)$. There were 73 discrepancies, with 12 significant over-treatments and 11 significant under-treatments. No consultation modality was found to be clearly better or worse than any other, and the outcomes measured at 5-10 days showed no significant differences between the three groups.

Discussion: These results indicate that minor injuries telemedicine is feasible and has a safety profile similar to conventional practice. No difference was detected in a wide range of clinical outcome measures, regardless of the treatment plan followed. Nevertheless, telemedicine consultations took significantly longer, occupying the time of senior medical staff, and were not universally successful, suggesting that where minor injuries telemedicine is adopted alternative arrangements may also need to be established. 


\section{BLUNT CERVICAL SPINE INJURIES IN SCOTLAND 1995-2000}

E. K. Drainer, C. A. Graham, P. T. Munro. Department of Accident and Emergency Medicine, Southern General Hospital, 1345 Govan Road, Glasgow, G51 4TF.

Background: In the Accident \& Emergency (A\&E) Department, the management of patients who have sustained head injuries $(\mathrm{HI})$ is often made more complicated by the suspicion of a cervical spine injury (CSI). Published literature quotes very variable incidences of CSI associated with HI. This study aimed to evaluate the incidence of CSI in patients sustaining blunt head injuries in a Scottish population.

Methods: Retrospective analysis of prospectively collected data for a five-year period from the Scottish Trauma Audit Group (STAG) database. Analysis included using logistic regression and other comparisons to investigate the relationship between Glasgow Coma Score (GCS) and the probability of a CSI.

Results: 5154 patients sustaining blunt head injuries met the inclusion criteria for the STAG database. 273 of the HI patients had associated CSI giving an overall incidence of $5.3 \%$. When patients with $G C S=3$ were excluded, there was no evidence of an increase in incidence of CSI with a lower GCS (logistic regression $X^{2}=0.09$, $p=0.75)$. However, when the $G C S=3$ group is included, statistical significance is reached because this group is almost three times more likely to have a CSI compared to the GCS $4-15$ groups ( $X^{2}$ (with continuity correction) $=62.9, p \leqslant 0.001$ )

Conclusions: When the admission GCS is above 3, the likelihood of having a CSI in patients with blunt head injuries is not predictable from admission GCS alone as there is no correlation between the level of GCS and the incidence of CSI. Patients with blunt head injuries who present with a GCS of 3 are much more likely to have a concomitant CSI. The overall incidence of $5.3 \%$ compares with published series from other countries.

\section{THE EFFECT OF WRIST RESTRAINT ON CARDIORESPIRATORY FUNCTION}

C. A. Meredith, J. Mayett, J. A. Hendry. Academic Department of Accident \& Emergency Medicine, St Mary's Hospital, South Wharf Road, London, W2 1NY.

Introduction: Emergency departments and the police sometimes encounter violent, agitated individuals for whom physical restraint is sometimes necessary. Case reports in the 1980s began to highlight deaths associated with restraint positioning, with subjects in many cases fighting up to the point of collapse. There are numerous factors contributing to the demise of restrained patients that remain undefined. This study aims to examine the effects of wrist restraint on cardiorespiratory responses during maximal exercise.

Methods: This is a randomised crossover experimental study. Twelve volunteers underwent an incremental maximal exercise test on a cycle ergometer, randomised to exercise either with their wrists restrained behind their back, in front or unrestrained. Outcome measures included minutes exercised, exercise stage reached, heart rate, Borg rating of perceived exertion and blood lactate level at each stage.

Results: Mean exercise time unrestrained was 18 min 44 secs (SD $2 \mathrm{~min} 58 \mathrm{sec}$ ), wrist restraints in front of the body $18 \mathrm{~min} 37 \mathrm{secs}$ (SD $3 \mathrm{~min} 1 \mathrm{sec}$ ), wrist restraints behind the back $17 \mathrm{~min} 9$ secs (SD $2 \mathrm{~min}$ $49 \mathrm{sec})$. The difference between wrist restraint behind the back compared with in front or unrestrained was statistically significant; $p=0.036$ and $p=0.001$ respectively. There was no difference in heart rate or Borg ratings between positions, however an increased blood lactate level was seen in the later stages of exercise (stages 3-5) when subjects had their hands restrained behind their back when compared to the unrestrained position ( $p=0.01, p=0.001, p=0.01$ respectively).

Discussion: This study has shown that when the wrists are restrained behind an individuals back, maximal exercise is limited. Higher lactate levels produced in this restraint position suggests that earlier anaerobic metabolism occurs when under conditions of maximal exercise. For violent individuals handcuffing in front of the body maybe safer

\section{A DIAGNOSTIC STUDY USING A MODIFIED RISK ASSESSMENT TOOL TO RULE OUT DVT IN PATIENTS PRESENTING TO AN EMERGENCY DEPARTMENT}

S. R. Jones, B. Lane, K. Mackway-Jones. Department of Emergency Medicine, Manchester Royal Infirmary, Oxford Road, Manchester, M13 9WL.

Aims: The aim of the study was to assess the validity of a modified risk assessment tool in patients presenting to the emergency department with symptoms and signs suggestive of a DVT.
Methods: Consecutive patients over 18 years of age attending the department were enrolled into the study. Exclusion criteria were inability to or refusal of consent, current anticoagulation therapy, or requirement of admission. At the time of assessing the patient the enrolling physicians undertook a structured risk assessment based upon the Wells score. Patients who had previously been treated for DVT or were current intravenous drug abusers were automatically considered to be high risk. All patients had a laboratory based D-dimer assay performed (IL Test D-Dimer) and were treated according to the result. A raised D-dimer level prompted a compression ultrasound scan (CUS) the same day. Patients with a normal D-dimer were discharged without anticoagulation and had a delayed CUS performed on day seven. Delayed CUS was the reference standard.

Results: The reference standard was applied to 294 patients. There were 72 patients diagnosed with DVT (prevalence 24\%). The results are shown in the table.

\begin{tabular}{lllll}
\hline & Sensitivity & Specificity & NPV & NLR \\
\hline D-Dimer alone & $96 \%(94-98)$ & $62 \%(57-68)$ & $98 \%(96-100)$ & 0.07 \\
$\begin{array}{l}\text { D-dimer and } \\
\text { Wells score }\end{array}$ & $96 \%(94-98)$ & $59 \%(53-65)$ & $98 \%(96-99)$ & 0.07 \\
$\begin{array}{l}\text { D-Dimer and } \\
\text { Modified Wells }\end{array}$ & $99 \%(97-100)$ & $50 \%(44-56)$ & $99 \%(98-100)$ & 0.03 \\
\hline NPV=negative predictive value, NLR=negative likelihood ratio, figures \\
given in brackets are the 95\% confidence intervals.
\end{tabular}

Conclusion: The results using the D-dimer assay alone are impressive but given the potentially fatal consequence of missing a DVT a more robust method must be found. Using the modified risk assessment tool can improve the safety of a rule out protocol.

Oral presentations

\section{Cardiovascular medicine}

\section{THE INDIVIDUAL VALUE OF DIAGNOSTIC TESTS USED IN A CHEST PAIN OBSERVATION UNIT PROTOCOL}

S. Goodacre, T. Locker, F. Morris, S. Campbell, K. Angelinin, J. Arnold. Accident and Emergency Department, Northern General Hospital, Herries Road, Sheffield, S5 7AU.

Background: The Northern General Chest Pain Observation Unit (CPOU) protocol tests selected patients presenting with acute chest pain using serial ECG/ST segment monitoring, CK-MB(mass) (at baseline and at least two hours later), troponin T (at least six hours after symptom onset) and exercise stress test (EST). This combination effectively detects acute coronary disease. We aimed to separately evaluate the individual constituents of the protocol.

\begin{tabular}{|lllll|}
\hline & & & $\begin{array}{l}\text { +ve } \\
\text { predictive } \\
\text { value }\end{array}$ & $\begin{array}{l}\text {-ve } \\
\text { predictive } \\
\text { value }\end{array}$ \\
\hline & Sensitivity & Specificity & & \\
\hline $\begin{array}{l}\text { Serial ECG/ST } \\
\text { monitor }\end{array}$ & $31.0 \%$ & $95.3 \%$ & $22.5 \%$ & $96.9 \%$ \\
CK-MB(mass) & $117.3-49.2)$ & $(93.4-96.6)$ & $(12.3-37.5)$ & $(95.3-98.0)$ \\
$(\geqslant 5 \mathrm{ng} / \mathrm{ml})$ & $(88.3-100)$ & $95.6 \%$ & $50.0 \%$ & $100 \%$ \\
& & $96.7-$ & $(37.5-62.5)$ & $(99.4-100)$ \\
Troponin T & $82.8 \%$ & $98.8 \%$ & $75.0 \%$ & $99.3 \%$ \\
$(\geqslant 0.1 \mathrm{ng} / \mathrm{ml})$ & $(65.5-92.4)$ & $(97.7-99.4)$ & $(57.9-86.7)$ & $(98.3-99.7)$ \\
Troponin T & $92.6 \%$ & $97.4 \%$ & $59.5 \%$ & $99.7 \%$ \\
$(\geqslant 0.04 \mathrm{ng} / \mathrm{ml})$ & $(76.6-97.9)$ & $(95.9-98.4)$ & $(44.5-73.0)$ & $(98.9-99.9)$ \\
\hline
\end{tabular}

Methods: All CPOU patients from 1/3/99 to 30/9/00 were followed up by case note review, for those admitted, and outpatient follow-up at three days for those discharged. Six months after attendance evidence of cardiac events were sought by computer search, case note review, and general practitioner contact. ECG and blood tests were compared in their diagnostic performance for acute myocardial infarction (AMI) by World Health Organisation criteria. All tests were compared for their ability to predict subsequent cardiac events over six months.

Results: 706 patients were assessed, $29(4.1 \%)$ with AMl and 15 $(2.1 \%)$ with a subsequent cardiac event. Diagnostic performance (95\% confidence intervals in parentheses) of serial ECG/ST 
monitoring, CK-MB(mass) and troponin $T$ are shown in the table below. Of all the tests, only EST predicted cardiac events over six months (relative risk, 6.63; 95\% confidence intervals 1.14 to 38.5).

Conclusion: Using conventional thresholds CK-MB(mass) has optimal sensitivity to rule-out AMl while troponin $T$ has superior specificity. However, a lower threshold for troponin T may be more appropriate in these low-risk patients. Serial ECG/ST monitoring adds little to our CPOU protocol. EST adds longer term predictive power once $\mathrm{AMI}$ is ruled out.

\section{'EVOLVING' MYOCARDIAL INFARCTION IN THE EMERGENCY DEPARTMENT TRUE SYNDROME OR TIME FOR BETTER EDU- CATION?}

A. A. Khan, A. Taylor, I. Barlow, T. B. Hassan, D. W. Hamer. The Department of Emergency Medicine, The General Infirmary at Leeds, Leeds, LS1 3EX.

Background: The National Service Frameworks for Coronary Heart Disease (NSF-CAD), has set high standards for the commencement of thrombolysis after arrival in the Emergency Department for patients with acute myocardial infarction (AMI). Previous work from this group has identified that a significant proportion of these patients have delays to their thrombolytic treatment due to 'evolving changes' on their initial electrocardiogram (ECG).

Objective: To identify if there had been a delay in thrombolysis in this group of patients because of 'evolving changes' or due to incorrect interpretation of the initial ECGs by medical staff.

Methods: A structured retrospective study was carried of patients who had been thrombolysed over a one year period. Notes of patients who had more than one ECG prior to initiating thrombolysis ' patients with evolving myocardial infarction' were obtained. The ECGs of these patients was then given to 2 blinded senior clinicians. The senior clinicians were asked to decide on which of the ECGs they would have commenced thrombolysis, and the reasons why

Results: A total of 54 patients were identified as having 'evolving myocardial infarctions'during the study period out of 280 patients that were thrombolysed. The median time to thrombolysis was 52 (9-290) minutes in these patients. The 2 senior clinicians agreed that they would have instituted thrombolysis at an earlier stage in 46 of these cases $(85.1 \%)$. Earlier decision making would have reduced the median time to thrombolysis to 20 (0-197) minutes. Patterns of 'missed' changes were identified.

Conclusions: A significant proportion of patients with 'evolving' changes of AMI could have been recognised earlier. A more focused educational package for Emergency Medicine staff and early senior involvement could improve their decision making and the time to thrombolysis.

\section{BODY SURFACE ELECTROCARDIOGRAPHIC MAPS IN INDUCED MYOCARDIAL ISCHAEMIA IN HUMANS}

S. Carley, K. Mackway-Jones, N. Curzon. Department of Emergency Medicine, Manchester Royal Infirmary, Oxford Road, Manchester M13 9WL

Introduction: The standard 12 lead ECG has remained unchanged for over 50 years, and its limitations in the diagnosis of infarction and ischaemia are well known. Body surface mapping (BSM) is a technique using 80 unipolar electrodes to sample from all areas of the thorax. Previous work has suggested that BSM has a greater sensitivity and specificity for the diagnosis of myocardial infarction. However, its ability to detect rapid transient ischaemia is unknown. The ability of BSM to detect rapid changes in myocardial perfusion is essential if it is to be used in the assessment of chest pain patients.

Aim: The aims of this study were to determine 1) If body surface mapping can detect transient changes in myocardial perfusion. 2) If characteristic changes in the body surface maps appear when different coronary vessels were occluded.

Methods: Patients had the BSM harness attached prior to the procedure. Transient ischaemia was induced during the balloon inflation phase of the angioplasty. The balloon was inflated for 1 minute. Maps were taken at 30 second intervals for 5 minutes or until the ischaemia had resolved. Ethical committee approval was obtained.

Results: 5 of the 7 patients recruited so far show clear and rapid transient change in their body surface maps. 1 patient developed a myocardial infarction during the procedure and shows continuing change in their maps. There are clear differences in maps taken from different arteries.

Conclusion: Body surface mapping shows rapid change in transient myocardial ischaemia. The maps show characteristic changes dependent upon which coronary artery is occluded.
AN ONGOING RANDOMISED, DOUBLE BLIND, PLACEBOCONTROLLED PILOT STUDY TO INVESTIGATE THE SAFETY OF RECOMBINANT HUMAN INTERLEUKIN-1 RECEPTOR ANTAGONIST IN PATIENTS WITH ACUTE STROKE

C. M. Libetta, C. J. Smith, H. C. A. Emsley, R. F. Drennan, N. J. Rothwell', P. J. Tyrrell. Department of Emergency Medicine, Hope Hospital, Salford M6 8HD; Manchester University Department of Medicine and Stroke Services, Hope Hospital, Salford M6 8HD; 'School of Biological Sciences, Manchester University, Oxford Road, Manchester.

Inflammation is important in the pathophysiology of neuronal injury after acute ischaemic stroke. We have recently completed a prospective study of 37 patients with ischaemic stroke who presented to the Emergency Department within 12 hours of symptom onset, which demonstrated that peripheral markers of inflammation are increased after cerebral ischaemia. Brain inflammation after ischaemic stroke is thought to be initiated by a complex cascade of pro-inflammatory mediators including cytokines e.g. interleukin-1 (IL-1), interlekin-6 (IL-6) and tumour necrosis factor- $\alpha$ (TNF- $\alpha$ ). Manipulation of the IL-1 system in rodent models of stroke provides strong evidence for its involvement in the pathogenesis of cerebral ischaemia. Peripheral administration of IL-1 receptor antagonist (IL-1 ra) significantly reduces infarct size in rats. A prospective, randomised, double-blind, placebo controlled pilot study is currently ongoing to investigate the safety of recombinant human interleukin-1 receptor antagonist (Anakinra) in patients with acute stroke who present within six hours of symptom onset. To date 12 patients have been randomised with no serious adverse events reported. This treatment may confer a neuroprotective effect by blocking the inflammatory cascade that occurs after stroke, thus reducing cell death in the ischaemic penumbra.

For novel stroke therapies to be effective it is likely that they will need to be administered within a very short time of symptom onset. For this reason collaboration is necessary between emergency physicians, stroke physicians and neurologists to ensure the feasibility of larger scale efficacy trials.

\section{ASSESSMENT OF rVLLa AS A UNIVERSAL HAEMOSTATIC AGENT IN A MODEL OF HAEMODILUTION}

S. Chillala', P.A. Evans', K. J. Pasi ${ }^{2}$. 'Accident \& Emergency Department, Leicester Royal Infirmary; ${ }^{2}$ Division of Haematology, University of Leicester, UK.

Haemostatic failure, secondary to large volume fluid replacement, is a major component to mortality and morbidity associated with blunt trauma. Recombinant factor V $\mathrm{lla}(\mathrm{rV} / \mathrm{la}$ ) is seen increasingly as a possible universal haemostatic agent that could act to reverse or prevent haemostatic failure associated with both the direct and dilution effects of the fluids used within the "Golden" hour of haemorrhagic shock.

Methods: We conducted a preclinical study to evaluate the potential role of $r V l l a$ as a universal haemostatic agent in a model of large volume fluid replacement using thrombelastography(TEG). TEG is a method of global haemostasis assessment, providing information on the rate of clot formation, clot strength and durability. Whole blood samples from normal donors were tested undiluted or diluted to $50 \%$ and $80 \%$ with haemaccel and $50 \%$ and $80 \%$ with normal saline. Global haemostasis was then assessed in the TEG analyser $\pm 90 \mu \mathrm{pg} / \mathrm{kg}$ rVlla added. Scanning electron microscopy was in addition used to assess the pattern of the fibrin network and deposition.

\begin{tabular}{lllll}
\multicolumn{4}{l}{ Addition of rVIla to replacement fluids } \\
\hline & $\begin{array}{l}50 \% \\
\text { (haem) }\end{array}$ & $\begin{array}{l}80 \% \\
\text { (haem) }\end{array}$ & $\begin{array}{l}50 \% \\
(\mathrm{NaCl})\end{array}$ & $\begin{array}{l}80 \% \\
(\mathrm{NaCl})\end{array}$ \\
\hline Initiation time & $\mathrm{p}=0.1617$ & $\mathrm{p}=0.1006$ & $\mathrm{p}=0.0507$ & $\begin{array}{l}\text { Significant } \\
\mathrm{p}=0.0256\end{array}$ \\
$\begin{array}{l}\text { Kinetics clot } \\
\text { formation }\end{array}$ & $\begin{array}{l}\text { Significant } \\
\mathrm{p}=0.0257\end{array}$ & $\mathrm{p}=0.0767$ & $\mathrm{p}=0.0593$ & $\mathrm{p}=0.3572$ \\
$\begin{array}{l}\text { Platelet reactivity } \\
\text { Significant }\end{array}$ & $\begin{array}{l}\text { Significant } \\
\mathrm{p}=0.0171 \\
\mathrm{p}=0.0081\end{array}$ & $\begin{array}{l}\text { Significant } \\
\mathrm{p}=0.043\end{array}$ & $\mathrm{p}=0.068$ \\
$\begin{array}{l}\text { Time to Maximum } \\
\text { clot strength. }\end{array}$ & $\mathrm{p}=0.1508$ & $\mathrm{p}=0.4265$ & $\mathrm{p}=0.27$ & $\begin{array}{l}\text { Significant } \\
\mathrm{p}=0.0482\end{array}$
\end{tabular}

Results: 62 samples were analysed.

- In general, dilution had a major effect on TEG parameters, these effects being ameliorated by the use of haemaccel rather than saline.

- Assessment of each group individually $\pm r V l l a$, showed that addition of $r$ Vlla significantly improved TEG parameters for the 
dilutions (see table) but no statistically significant change in TEG parameters for undiluted whole blood.

- Scanning electron microscopy of samples demonstrated increased fibrin deposition with the addition of rVlla.

Conclusion: Addition of $\mathrm{rVlla}$ appears to improve markers of global haemostasis as well as demonstrating increased fibrin deposition in this model of large volume fluid replacement with associated haemodilution. Further work is required to assess its potential value as a universal haemostatic agent in the setting of trauma with large volume fluid replacement.

\section{CAPILLARY REFILL: REASSESSMENT OF AN OLD TEST? A PRE- LIMINARY REPORT}

C. R. FitzSimmons, J. Morcombe, K. Gracie, D. P. Burke. A\&E Department, Sheffield Children's Hospital, Western Bank, Sheffield S10 2TH.

Capillary refill is a simple clinical test advocated for use in the assessment of circulatory status in the ill or injured child by the APLS, PALS and ATLS courses. However its validity has recently been questioned by several sources. We are currently undertaking a programme to assess and validate the use of a variety of physiological and clinical parameters in the initial assessment of children in A\&E. As part of a larger study of capillary refill (including an assessment of the reliability of the end-point) we set up a study to determine the normal range for the test in the paediatric A\&E population.

Literature review: References exist to 'skin blanching to pressure' in the circulatory assessment of the shocked patient as far back as 1947. The first description of capillary refill as it is now known was in 1980 when Champion used it as one of the five physiological parameters in the Trauma Score. It was subsequently eliminated from the Revised Trauma Score in 1990. In 1988 Baraff stated that the two second upper limit for refill time was in fact arbitrary. Since then studies have been done in neonates, infants and adults to define the normal range. Only one study was found defining the normal range in children and no reference could be found to any studies in an A\&E setting.

The normal range for capillary refill: We undertook a prospective review of capillary refill times (CRT) in children triaged on presentation to the A\&E department at Sheffield Children's Hospital. All refill times were measured with a stopwatch to the nearest $1 / 10$ th second in a standardised manner, pressure being applied to the child's forehead for a timed 5 seconds. All attenders were included. $272(54.7 \%)$ attended with injuries/minor trauma and 225 (45.3\%) with medical complaints. The results for the first 497 children are as follows: Male : female ratio 1.5: 1: Median age 5 years; Median CRT 0.9 seconds (range 0.2s-2.6s); Number of times over 2 seconds: 4 (2.1s, 2.1s, $2.3 \mathrm{~s}$ and $2.6 \mathrm{~s}$ )

Conclusion: An upper limit of two seconds for normal capillary refill seems to be acceptable, if not a little high in the general paediatric A\&E population. The four abnormal results were all found to be in children under 1 year and none of them were seriously unwell.

\section{Trauma and Others}

\section{ROLE FOR ULTRASOUND IN THE CLINICAL MANAGEMENT OF CHEST INJURY}

T. H. Rainer, J. Griffiths, E. Lam, P. K. W. Lam, C. E. Metreweli. Accident and Emergency Medicine Academic Unit, Department of Diagnostic Radiology and Organ Imaging, and Centre for Clinical Trials and Experimental Research, The Chinese University of Hong Kong and Prince of Wales Hospital, Hong Kong.

Background: Emergency physicians are frequently unable to determine whether musculoskeletal chest wall injury involves a fracture and whether fractures adversely affect prognosis compared with soft tissue injury alone.

Objectives: Firstly, to compare initial clinical assessment, plain radiography and early ultrasound in the diagnosis of chest wall fracture using late ultrasound as the gold standard; secondly, to determine whether chest wall fracture is associated with significant respiratory complications or delayed return to work.

Design: Prospective observational study.

Setting: Emergency department of a university hospital in the New Territories of Hong Kong.

Subjects: Patients (aged > 10years) with blunt chest wall injury

Main outcome measures: Primary outcome measure was the presence or absence of thoracic wall fracture. Secondary outcome measures were respiratory complications and time to return to work.
Results: 115 subjects, 70 (61\%) male, mean age 47.8 years (SD 19.5). In univariate analysis, the odds of detecting rib/sternal fractures were: $4.3(95 \% \mathrm{Cl} 1.76-10.53)$ for age $>40$ years; $4.49(\mathrm{Cl}$ 1.72-11.75) for pain on coughing; $2.96(\mathrm{Cl} 1.24-7.11)$ for delayed presentation $>24$ hours; 8.18 (Cl 1.05-64.05) for clinical suspicion alone; and $27.7 \mathrm{CCl} 5.3-144.1)$ for early ultrasound. Multivariate logistic regression analysis demonstrated that the likelihood of detecting a fracture with pain on coughing was $4.95(p=0.03)$ and with early ultrasound was $13.71 \quad(p=0.0002)$. The correct classification rate for detecting a fracture was $97.14 \%$, for predicting no fracture was $33.33 \%$, with an overall correct classification rate of $87.80 \%$ (overall likelihood ratio 27.1, p<0.0001; Pearson Goodness-of-Fit $43.6,0.9989)$. In patients with a fracture the odds of a persistent cough was $3.61 \mathrm{Cl}$ 1.13-11.49) but there was no significant difference in sputum production, exertional dyspnoea or infective symptoms. The mean time off work for patients with fractures was 26.2 (SD 32.3) days compared with 7.1 (SD 13.0) days in those patients without fractures ( $p=0.0007)$.

Conclusion: Increasing age, pain on coughing and delayed presentation may be associated with a significant risk of chest wall fracture. Early ultrasound detects fractures accurately and patients with fractures are likely to require prolonged absence from work.

EVALUATION OF FOCUSSED ASSESSMENT WITH SONOGRAPHY IN TRAUMA IN THE EMERGENCY ROOM - THE FASTER TRIAL

J. Brenchley, A. Walker, T. B. Hassan, H. Venables, J. Wilson, H. Irving, J. P. Sloan, W. Hamer. Leeds General Infirmary, Great George Street, Leeds LSI 3EX.

Background: A limited ultrasound scan to document the presence of intra-peritoneal fluid in patients following blunt abdominal trauma is an accepted part of resuscitation in the USA and continental Europe. The technique is used to identify the presence of intra-peritoneal free fluid which would indicate a significant injury. There are no studies to describe the use of this technique in the UK emergency department setting.

Objective: To determine the accuracy of the technique when performed by a group of emergency physicians in the United Kingdom

Setting and subjects: The emergency department of a large teaching hospital seeing 105,000 new patients per year. All patients over the age of 16 admitted to the resuscitation room as a result of blunt trauma.

Methods: All eligible patients had a focussed ultrasound scan performed by a senior emergency physician at the end of the primary survey. The results were non-contributory to management unless free fluid was seen in a patient who would otherwise have had no further abdominal investigation.

Main outcome measures: Results of the FAST scan are compared to current diagnostic methods including clinical examination, observation, CT, laparotomy (and post mortem).

Results: Thus far, 110 patients have been entered into the study. The mean age of the patients was 43.9 and mean ISS was 15 (range 1-66), Seven patients have had positive scans (mean ISS 29) including one false positive. There have been no false negative results and sensitivity is thus 100\%. Specificity is $99 \%$ (NPV 100\%, PPV $86 \%$ ). Five patients went on to have a laparotomy.

Conclusions: FAST is a rapid non-invasive method to identify intraabdominal injury. The technique can be easily taught and skills maintained in an emergency department setting in the UK.

\section{RAPID SEQUENCE INTUBATION IN SCOTTISH URBAN EMER-} GENCY DEPARTMENTS

C. A. Graham, D. Beard, A. Oglesby, S. B. Thakore, J. P. Beale, J. Brittliff, M. A. Johnston, D. W. McKeown, T. R. J. Parke. Department of Accident \& Emergency Medicine, Southern General Hospital, 1345 Govan Road, Glasgow G51 4TF.

Background: Airway care is the cornerstone of resuscitation. In UK practice, anaesthetists and emergency physicians provide this care. The aim of this study was to determine current practice for rapid sequence intubation (RSI) in emergency departments in Scotland.

Methods: Two year, multi-centre, prospective observational study of endotracheal intubation in the emergency departments of seven Scottish urban teaching hospitals.

Results: 1631 patients underwent an intubation attempt in the emergency department and 735 patients satisfied the criteria for RSI. Emergency physicians intubated 377 patients and anaesthetists intubated 355 patients. There was no difference in median age 
between the groups but there was a significantly greater proportion of males $(73.2 \% \vee 65.3 \%, p=0.024)$ and trauma patients $(48.5 \%$ v $37.4 \%, p=0.003$ ) in the anaesthetic group. Anaesthetists had a higher initial success rate $(91.8 \% \vee 83.8 \%, p=0.001)$, achieved more good views (defined as Cormack-Lehane Grade I and II) at laryngoscopy $(94.0 \%$ v $89.3 \%, p=0.039)$ and experienced fewer immediate complications than emergency physicians $(8.7 \%$ v $12.7 \%, p=0.104)$. Emergency physicians intubated a higher proportion of patients with physiological compromise $(91.8 \%$ v $86.1 \%, \mathrm{p}=0.027)$ and a higher proportion of patients within 15 minutes of arrival $(32.6 \% \vee 11.3 \%$, $\mathrm{p}<0.0001)$.

Discussion: Anaesthetists achieve more good views at laryngoscopy with higher initial success rates during RSI, but emergency physicians perform RSI on a higher proportion of critically ill patients and a higher proportion of patients within 15 minutes of arrival. Complications are fewer in the anaesthetists group, but this may be related to differences in patient populations. Training issues for RSI in the emergency department and emergency airway care will be discussed. Complication rates for both groups are in keeping with previous studies.

\section{CAN EMERGENCY SENIOR HOUSE OFFICERS CLINICALLY DIAGNOSE STRUCTURAL PATHOLOGY ACCURATELY IN ACUTE TRAUMATIC KNEE EFFUSIONS?}

J. P. Gray, R. Fitzpatrick, A. J. Liddicoat, G. R. Cherryman, P. A. Evans. Emergency Department, Leicester Royal Infirmary, Infirmary Square, Leicester LE1 5WW, United Kingdom.

Introduction: Acute traumatic knee effusion (ATKE) presents a diagnostic dilemma, even for the experienced emergency doctor. Accurate diagnosis of structural damage to the knee allows timely referral to definitive care, reduction in long term morbidity and an earlier return to full activity. The objective of our prospective study was to evaluate if $\mathrm{SHO}$ s can be taught to diagnose structural injury accurately in ATKEs, following induction, using a standardised protocol for knee evaluation. Magnetic resonance imaging (MRI) was utilised in this study as a reference diagnostic and is a non-invasive, rapid, non-irradiating diagnostic tool with $80-95 \%$ sensitivity, approaching that of arthroscopy.

Methodology: Following ethical committee approval, patients presenting with an ATKE were assessed by an Emergency SHO, who made a clinical diagnosis. All patients were reviewed by an Emergency Registrar or Consultant using the standardised protocol, by a mean of 48 hours from initial consultation. A clinical diagnosis was again made along with knee aspiration and dual echo sequence MRI performed.

Results: 57 patients were enrolled and assessed using clinical, needle aspiration and MRI criteria. There were $26(45.6 \%)$ positive MRI scans for structural insult to the knee. SHOs identified 11 structural insults accurately (sensitivity $=42.3 \%$ ), while Registrar or Consultant identified 15 structural insults accurately (sensitivity $=57.7 \%$ ), when compared with MRI findings. There were 31 (54.4\%) MRI scans showing no structural injury to the knee and all grades of clinician in this group diagnosed some structural abnormality to be present (specificity $=0 \%$ ). Mean aspirate volume was $39.3 \mathrm{mls}$ in the ATKEs with structural injury, compared to $35.9 \mathrm{mls}$ in the ATKEs with no structural injury.

Conclusion: Irrespective of grade of Emergency clinician, there was a significant shortfall in the diagnosis of specific structural injury and a complete inability to identify knees with no structural insult, compared with MRI. Surprisingly, there was no relation between volume or morphology of knee aspirate and presence or absence of structural impairment on MRI. Notably, more than half the ATKEs had no structural insult apparent on MRI. This study emphasises the challenge posed by ATKE in the Emergency Department setting.

\section{INTEROBSERVER VARIABILITY IN EXAMINATION OF THE INJURED SCAPHOID}

K. Gow, S. Carley, K. Mackway-Jones. Department of Emergency Medicine, Manchester Royal Infirmary, Oxford Road, Manchester M13 9WL.

Introduction: Scaphoid fracture is an important diagnosis to make in the patient presenting with an injured wrist. It is widely known that initial radiographs of the wrist fail to spot clinically important fractures and as a result the initial decision to immobilise or not is made on clinical grounds. A number of tests for scaphoid injury have been described. However, their reliability between examiners has not previously been investigated.

Aim: The aims of this study were to determine 1) the interobserver variability of doctors using different clinical tests for scaphoid injury 2) if the differences in observer findings were due to differences in pressure applies during examination.
Methods: Patients presenting with a suspected scaphoid fracture were eligible for the study. 2 doctors independently examined the patient for anatomical snuffbox tenderness (ASBT), thumb compression tenderness (TCC) and scaphoid tubercle tenderness (STT). Interobserver variability was calculated for these tests. The second doctor was blinded to the findings of the first. In addition a pressure sensor was placed in an anatomical model of a wrist. Doctors were asked to examine the wrist as they would when performing an ASBT test. The amount of pressure applied was recorded.

Results: 24 patients were examined. Substantial agreement between physicians was shown for ASBT $(k a p p a=0.664)$ and SCC $(\mathrm{kappa}=0.739), \mathrm{TCC}$ showed fair agreement $(\mathrm{kappa}=0.289)$. The range of pressures measured on the anatomical model showed a wide range, with pressures of 4-80 Newtons being applied.

Conclusion: Clinical tests for the injured scaphoid show fair to substantial agreement between observers. The discrepancy between observers may be due to the difference in force used to apply the test.

THE EFFECTS OF ANAESTHETICS ON THE ACUTE BLOOD PRESSURE RESPONSES TO HAEMORRHAGE IN THE INJURED RAT

I. Igbinedion, E. Kirkman', R. Little. MRC Trauma Group, Manchester; Department of Biological Sciences, Durham.

The magnitude of blood loss and its compensation are important factors in determining outcome after injury. It is known that both brain and peripheral tissue injury can themselves modify the acute cardiovascular response to blood loss. Agents such as morphine, which are used in the early treatment of the injured patient can also modify the cardiovascular response and increase mortality. Anaesthetic agents are also used in the injured patient before the magnitude of blood loss is assessed and appropriate fluid resuscitation given. In the present study the effects of a number of anaesthetics (of physiological and clinical relevance) on the acute blood pressure response to haemorrhage have been studied in the injured rat.

32 male Wistar rats $(241$ - $258 \mathrm{~g})$ were briefly $(30 \mathrm{~min}$ ) anaesthetised with isoflurane $3.5 \%$ and $2 \%$ in $\mathrm{O}_{2}$ for induction and maintenance respectively) and cannulae placed in a lateral tail vein and the tail artery. The isoflurane was then discontinued and anaesthesia maintained with either chloralose $(70 \mathrm{mg} / \mathrm{kg} . \mathrm{n}=8)$, propofol $(48-52.5 \mathrm{mg} / \mathrm{kg} / \mathrm{h} . \mathrm{n}=8)$, or saffan $(19-22 \mathrm{mg} / \mathrm{kg} / \mathrm{h} . \mathrm{n}=$ 8) intravenously or sevoflurane $\left(3.5-4.5 \%\right.$ in $\left.\mathrm{O}_{2} \mathrm{n}=8\right)$ by inhalation. The rats were then allowed to stabilise for $1 \mathrm{~h}$ before injury was produced by the application of bilateral hind-limb tourniquets. Ten minutes later a $40 \%$ haemorrhage was started at a rate of 0.12 $\mathrm{ml} / 100 \mathrm{~g}$ body weight $/ \mathrm{min}$ ( $2 \%$ blood volume $/ \mathrm{min}$ ). Body temperature was maintained constant throughout the procedure.

The blood loss at which arterial blood pressure first fell was significantly (one way ANOVA, $P<0.05)$ lowest for chloralose $(9.9 \pm 0.1 \%$ blood volume, mean \pm SEM), intermediate for saffan $(23.0 \pm 0.2 \%)$ and propofol $(23.1 \pm 0.2 \%)$ and greatest for sevoflurane $(26.3 \pm$ $0.2 \%)$.

In conclusion the ability to maintain arterial blood pressure during a progressive haemorrhage in the injured rat is differentially modified by different anaesthetic agents.

\section{MEDICAL COUNTERMEASURES TO THE BIOTERRORIST THREAT: THE ROLE OF ACCIDENT AND EMERGENCY MEDI- CINE}

R. C. Spencer, N. F. Lightfoot. Public Laboratory Service, Level 8, Bristol Royal Infirmary, Marlborough Street, Bristol BS2 8HW.

The bombings of the World Trade Center, New York in 1993 and the Alfred P Murrah Federal Building Oaklahoma City in 1995 were a rude and violent awakening for the Western World, to the threats now posed by the fundamentalist and religious apocalytic terrorist groups. This real threat was re-emphasised, if any was needed, by the Aum Shinrikyo sarin attack on Toyko's subway system in 1995. Experts have argued that moral and political constraints have inhibited organisations from employing WMD. Recently however there has been increasing recognition that this model may not apply to all terrorist groups, who find mass murder consistent with their objectives. Although it would appear the risk of a biological attack remains low, the potential consequences could be overwhelming. The casualty numbers in biological terrorism are potentially enormous: $10^{3}, 10^{5}, 10^{6}$, rather than a few hundred. Yet a rational response must be available and preparedness has been identified as a priority by $\mathrm{DH}$ which has recently issued such guidelines to the NHS

The aim of this presentation is to raise awareness and define the role of accident and emergency departments in coping with the threat. 